\title{
El Término Músculo y su Coherencia Interna: Una Sugerencia a Terminologia Histologica
}

\author{
The Term Muscle and its Internal Coherence: A Suggestion to Terminologia Histologica
}

\author{
Rodrigo Muñoz-Cofréé, ${ }^{1,2}$ Ignacio Roa ${ }^{1,3}$; Christopher Nicholson ${ }^{4}$; Daniel Conei ${ }^{1,5}$; \\ Marcelo Parra Véliz ${ }^{1}$; Máximo Escobar Cabello² \& Bélgica Vásquez ${ }^{6}$
}

MUÑOZ-COFRÉ, R.; ROA, I.; NICHOLSON, C.; CONEI, D.; PARRA-VÉLIZ, M.; ESCOBAR-CABELLO, M . \& VÁSQUEZ, B. El término músculo y su coherencia interna: Una sugerencia a Terminologia Histologica. Int. J. Morphol., 37(1):128-135, 2019.

RESUMEN: Terminologia Histologica $(\mathrm{TH})$ fue confeccionada siguiendo las indicaciones del Comité Federativo Internacional en Terminología Anatómica (FIPAT), sin embargo, no está exenta de errores e incongruencias. Lo anterior se evidencia al analizar el término músculo (TM) cuando se considera: el idioma en que se encuentra, número de palabras utilizadas o si las palabras que la componen efectivamente describen la forma de su estructura. En este contexto, el objetivo de esta investigación fue analizar en la TH el TM y su contexto histórico para proponer cambios consistentes con los lineamientos de la FIPAT. Desde el punto de vista histórico, fue descrito primeramente como un tejido contráctil, con acción capaz de originar movimiento; conformado por dos tendones y un relleno de carne. En el Renacimiento fueron incorporados los ligamentos, nervios, venas y arterias como parte del tejido y en el siglo XIX se reconoce la existencia de dos tipos de músculo, voluntario e involuntario; finalmente, Testut incorpora el término estriado a las fibras musculares. Las principales hallazgos indican que las palabras liso, esquelético y cardíaco tiene su origen en el griego y fueron latinizadas, sin embargo, liso tiene su equivalente en latín que es levis; en el caso del término esquelético proponemos reemplazarlo por osseus, que significa relativo al hueso, ya que es una palabra latina y entrega mayor información para la comprensión de la estructura; el término estriado visceral no cardíaco sería una redundancia; los vocablos visceral y cardíaco expresan relación y/o ubicación del músculo estriado y no forma. Pese a esto, el análisis histórico indica que estos conceptos fueron interiorizados desde el siglo XV y XVI aproximadamente, por lo que sugerir su cambio o eliminación es complejo debido a la cantidad de años que han sido utilizados. En este contexto, sería prudente analizar la posibilidad de ir solamente sobre las redundancias, así el término tejido muscular estriado quedaría con tres subordinadas; tejido muscular estriado óseo, tejido muscular estriado visceral y tejido muscular estriado cardiaco.

PALABRAS CLAVE: Terminologia Histologica; Músculo; Historia.

\section{INTRODUCCIÓN}

En las ciencias morfológicas los epónimos, en su mayoría, han sido acuñados en honor a su descubridor. Estos a menudo no tienen base descriptiva y, por tanto, no pueden asociarse, generando finalmente la simple memorización de esta estructura (Duque et al., 2002). Intentando dar resultado a esta problemática, la Federación Internacional de Asociaciones de Anatomistas (IFAA) estableció una serie de indicaciones con el propósito de regular las denominaciones de estructuras en morfología y así facilitar un lenguaje universal (Roa et al., 2016; Montemayor et al., 2016). En el campo de la Histología, este esfuerzo comenzó en el año 1965, cuando el profesor Eliseev fue elegido representante del subcomité de Histología del VIII Congreso Internacional de Anatomía. Se propuso estructurar los términos utilizados en el área, generando así la primera Nomina Histologica, la cual se publicó en el año 1977. En los años 1983 y 1989 se publicaron la segunda y tercera ediciones. Luego, con la creación del Comité Federativo Internacional en Terminología Anatómica (FIPAT), en el 2008 se crea la primera edición de la Terminologia Histologica $(\mathrm{TH})$, abarcando la Citología, Histología General e Histología Especial (Vásquez \& del Sol, 2014).

\footnotetext{
${ }^{1}$ Programa de Doctorado en Ciencias Morfológicas, Universidad de La Frontera, Temuco, Chile.

${ }^{2}$ Programa de Especialidad en Función-Disfunción Ventilatoria, Universidad Católica del Maule, Talca, Chile.

${ }^{3}$ Departamento de Ciencias Básicas Biomédica, Facultad de Ciencias de la Salud, Universidad de Talca, Talca, Chile.

${ }^{4}$ Núcleo de Idiomas, Facultad de Estudios Interdisciplinarios, Universidad Mayor, Temuco, Chile.

${ }^{5}$ Departamento de Ciencias Morfológicas, Facultad de Medicina y Ciencia, Universidad San Sebastián, Puerto Montt, Chile.

${ }^{6}$ Facultad de Ciencias de la Salud, Universidad de Tarapacá, Arica, Chile.
} 
La FIPAT sugiere el latín como idioma base para todas las terminologías, aunque gran parte de los términos derivan del griego (Rodríguez, 2003). Si bien esta norma busca la uniformidad, no considera un punto importante: tanto en Europa como en América, la mayoría de los estudiantes universitarios no tienen los conocimientos mínimos de griego y de latín; por tanto, los pre como post graduandos se encuentran poco familiarizados con la raíz griega o latina de los términos, hecho que además de dificultar el aprendizaje, en el futuro contribuirá a la problemática de la denominación de estructuras nuevas (Duque et al.).

La mayoría de los términos griegos y latinos fueron acuñados hace más de 2000 años, y en anatomía muchos de estos hacen referencia a plantas o animales. Por ejemplo, el término cóclea hace referencia a la concha de varias especies de moluscos, o músculo que semánticamente significa ratón pequeño (Diccionario Médico Universidad de Salamanca, 2018). En este último, los griegos observaron una semejanza entre el músculo bíceps y un ratón, en donde el vientre del músculo sería el cuerpo del ratón y el tendón su cola (Galbiati, 2014). Específicamente, el músculo es el tejido más abundante en el cuerpo humano y su función principal es la de generar movimiento. Por tanto, participa en funciones como: la respiración, la contracción cardiaca y el tránsito del bolo alimenticio, entre otras (Wang et al., 2012). Sin embargo, en sus inicios el término músculo (TM) estaba asociado solo al tejido que se insertaba al esqueleto a través de sus tendones (Micheli-Pellegrini, 2011). Años más tarde, se planteó la existencia de músculos distintos al esquelético. Posteriormente, con la invención del microscopio, se visualizó la micro-estructura del músculo (Caputo, 2011), situación que además de generar un avance en la comprensión de este tejido, también contribuiría a la designación de términos más específicos en relación a sus distintos tipos.

Lamentablemente, esta evolución se ha desarrollado de manera independiente a la $\mathrm{TH}$ o han tenido escasos puntos de encuentro. Esto se evidencia al analizar el TM en la $T H$, aquí se contradicen algunas de las sugerencias propuestas por la FIPAT: el idioma en que se encuentra, número de palabras utilizadas o si las palabras que la componen efectivamente describen la forma de su estructura. En este contexto, el objetivo de esta investigación fue analizar en la $T H$ el TM y su contexto histórico para proponer cambios consistentes con los lineamientos de la FIPAT.

\section{MATERIAL Y MÉTODO}

El TM se identificó en «Terminologia Histologica: International terms for human cytology and histology», don- de se analizó la conformación del término y los subordinados de este (FIPAT, 2008). Para dar el contexto semántico y gramatical del TM y sus subordinados, se utilizó el Diccionario Médico-Biológico, Histórico y Etimológico de la Universidad de Salamanca (2014). Posteriormente, en el mismo sitio se buscó documentación histórica en relación al uso del TM. De manera complementaria, se efectuó una búsqueda bibliográfica, no sistemática, de libros y artículos científicos en las bases de datos MEDLINE y SciELO, donde las palabras utilizadas fueron: músculo, historia del término músculo, músculo cardíaco, músculo esquelético, músculo liso y músculo estriado. El resultado de esto se registró en una tabla según año de publicación, nombre del autor, referencia de la obra y descripción del TM. Para la construcción de la tabla se consideró como autor al investigador que realizó la definición.

\section{RESULTADOS}

En $T H$, el TM se encuentra dentro del capítulo Histologia generalis (Histología general), el cual se subdivide en Cellulae precursoriae (Células precursoras), Textus epitelialis (Tejido epitelial), Textus connectivi atque sustinentes (Tejido conectivo y de sostén), Structurae haematolymphoideae (Complejo hematolinfoide), Textus muscularis (Tejido muscular) y Textus nervosus (Tejido nervioso). En el ítem Tejido muscular, en primera instancia se muestran estructuras celulares y subcelulares (Myocytus), para posteriormente subdivirse en dos tipos de tejidos: H2.00.05.1.00001 Textus muscularis levis; Textus muscularis nonstriatus (Tejido muscular liso) y H2.00.05.2.00001 Textus muscularis striatus (Tejido muscular estriado). Este último se subdivide en H2.00.01.0.00009 Cellula myogenica precursoria (Célula miogénica precursora), H2.00.05.2.00002 Textus muscularis striatus skeletalis (Tejido muscular estriado esquelético), H2.00.05.2.00003 Textus muscularis striatus visceralis (Tejido muscular estriado visceral) (Tabla I).

En el caso del término Tejido muscular estriado, la $T H$ realiza una aclaración, señalando que esta clasificación reconoce la presencia de tejido muscular estriado visceral no cardiaco, como en el músculo estriado esofágico, anal externo y en esfínteres uretral. En Tejido muscular estriado no cardiaco, explica que este término incluye al Tejido muscular estriado visceral y músculo estriado esquelético.

El análisis etiológico indica que músculo es una palabra grecolatina compuesta del griego "mū-s" [ $\mu \nu \varsigma]$ cuyo significado es "ratón" y "culus" del latín, que corresponde a “pequeño". Los términos provenientes del griego correspon- 
Tabla I. División del tejido muscular propuesta por Terminologia Histologica.

\begin{tabular}{lll}
\hline & NOMINA LATINA & EQUIVALENTE EN INGLÉS \\
\hline H2.00.05.1.00001 & TEXTUS MUSCULARIS LEVIS: TEXTUS & SMOOTH MUSCLE TISSUE \\
& MUSCULARIS NONSTRIATUS & \\
$\mathbf{H 2 . 0 0 . 0 5 . 2 . 0 0 0 0 1}$ & TEXTUS MUSCULARIS STRIATUS & STRIATED MUSCLE TISSUE \\
$\mathbf{H 2 . 0 0 . 0 1 . 0 . 0 0 0 0 9}$ & Cellula myogenica precursoria & Myogenic stem cell \\
$\mathbf{H 2 . 0 0 . 0 5 . 2 . 0 0 0 0 2}$ & Textus muscularis striatus skeletalis & Skeletal striated muscle \\
$\mathbf{H 2 . 0 0 . 0 5 . 2 . 0 0 0 0 3}$ & Textus muscularis striatus visceralis & Visceral striated muscle \\
$\mathbf{H 2 . 0 0 . 0 5 . 2 . 0 0 0 0 4}$ & Textus muscularis striatus cardiacus & Cardiac striated muscle \\
$\mathbf{H 2 . 0 0 . 0 5 . 2 . 0 0 0 0 5}$ & Textus muscularis striatus visceralis non cardiacus & Noncardiac visceral striated muscle \\
\hline
\end{tabular}

den a: "Esquelético", conformado por "esqueleto" [ $\sigma \kappa \varepsilon \lambda \varepsilon \tau$ ] que significa "desecado" e "ico" [1кo] "relativo a"; "Cardiaco", compuesto de "cardia" $[\kappa \alpha \rho \delta 1 \alpha]$ "corazón" y "aco" [ $\alpha \kappa]$ "relativo a"; y "Liso", donde "liso-a" $[\lambda \iota \varsigma]$ significa "sin arrugas o asperezas". Los términos provenientes del latín corresponden a: "Estriado", el cual viene de "stria" que significa "surco, raya, ranura o acanaladura"; y "Vísceras" de "uiscer(a)" que hace referencia a los órganos contenidos en las principales cavidades del cuerpo humano (Tabla II).

Desde el punto de vista histórico, en la Tabla III se pueden observar los cambios que ha tenido el TM a lo largo del tiempo. En la antigua Grecia Erasístrato fue el primer científico en describir al tejido muscular como contráctil, acción capaz de originar movimiento. Posterior a esta definición, Claudius Galenus lo caracterizó como el conjunto conformado por dos tendones y un relleno de carne, el cual podía generar fuerza en dirección de sus fibras. Ya en el Renacimiento, científicos como Andreas Vesalius, Bernardino Montana y Realdu Columbi agregaron a la definición existente, vale decir el conjunto de tendones y fibras musculares, incluyeron nervios, venas y arterias. En el siglo XVII, Giovanni Borelli y Manuel de Porras dividieron al músculo en tercios: una parte inicial o cabeza, una parte media o vientre y una parte final o cola. Finalmente, en el siglo XIX Henry Grey, Testut señalaron que el músculo al contraer sus fibras es capaz de producir dos tipos de movimiento: voluntario e involuntario, conformando la definición actual.

Tabla II. Origen del Término Músculo y su subdivisión.

E squeléti co, del griego

esqueleto [_ó] : desecado

ico [iko]: relativo a

Músculo

mu-s [muV] del griego

ratón;

culus del latín

pequeño
Cardíaco, del griego

cardia [_ ] corazón
aco $\left[\_\right.$relativo a

Estriado, del latín

stria: surco, raya, ranura o acanaladura

\section{Liso, del griego y latín}

liso-a [ ] $]$ : sin arrugas o asperezas

levis: liviano, ligero

Vísceras, del latín

uiscer(a): los órganos contenidos en las principales cavidades del cuerpo humano 
Tabla III. Desarrollo histórico del Término músculo.

\begin{tabular}{|c|c|c|}
\hline Año & $\begin{array}{l}\text { Investigador } \\
\text { Obra }\end{array}$ & Descripción \\
\hline $\begin{array}{l}304-250 \\
\text { a.C }\end{array}$ & Erasístrato & $\begin{array}{l}\text { Responsables del movimiento. Su c ontracción generaba movimiento de la } \\
\text { caja torácica y la respiración. }\end{array}$ \\
\hline $\begin{array}{l}\text { 129-200 } \\
\text { d.C. }\end{array}$ & Claudius Galenus & $\begin{array}{l}\text { Es el conjunto formado por los tendones y su relleno de carne en la parte } \\
\text { media. Son la principal fuente de movimiento, ellos generan fuerza en la } \\
\text { dirección de sus fibras por contracción. }\end{array}$ \\
\hline 1542 & $\begin{array}{l}\text { Andreas Vesalius } \\
\text { Humani corporis fabrica }\end{array}$ & $\begin{array}{l}\text { Órgano del movimiento voluntario. Está formado por nervios, ligamentos, } \\
\text { carnes, venas y arterias. La carne está dividida en fibras múltiples, conforme } \\
\text { a la naturale za del ligamento, a las cuales contiene y da firmeza. }\end{array}$ \\
\hline 1551 & $\begin{array}{l}\text { Bernardino Montana } \\
\text { Libro de la anatomía del hombre }\end{array}$ & $\begin{array}{l}\text { Se define en castellano como murezillo. Carne verdadera ubicada en } \\
\text { miembros y el cuerpo. Está compuesto por nervios, ligamentos, arterias y } \\
\text { venas, cubierto por un panículo que encierra todo, es tibio y rojo debido a la } \\
\text { abundante sangre. Su función es mover los miembros del cuerpo donde la } \\
\text { voluntad quiera. }\end{array}$ \\
\hline 1559 & $\begin{array}{l}\text { Realdus Columbi } \\
\text { De Re Anatomica Libri } X V\end{array}$ & $\begin{array}{l}\text { Instrumento del movimiento voluntario, a tr avés de su c ontracción. Está } \\
\text { conformado por carne fibrosa, nervios, ligamentos venas y arterias. }\end{array}$ \\
\hline 1680 & $\begin{array}{l}\text { Giovanni Borelli } \\
\text { De Motu Animalium }\end{array}$ & $\begin{array}{l}\text { Está formado por tendones, membranas, carne, venas, arterias y nervios. El } \\
\text { inicio e inserción del músculo son sus tendones, en su parte intermedia está } \\
\text { el vientre que es una came musculosa. Su interior está formado por } \\
\text { fascículos prismáticos de fibras tendíneas, estas se unen al hueso o a fibras } \\
\text { carnosas. }\end{array}$ \\
\hline 1733 & $\begin{array}{l}\text { Manuel de Porras } \\
\text { Anatomía Galénico-Moderna }\end{array}$ & $\begin{array}{l}\text { Es una parte orgánica, e instrumento del movimiento voluntario. } \\
\text { Comúnmente los músculos tienen a lo menos dos tendones, por medio de los } \\
\text { cuales se ligan a las partes vecinas, que frecuentemente son huesos. Aquel } \\
\text { hueso, o pa rte, a la que se liga el tendón, y hacia quien se hace la } \\
\text { contracción, se llama principio o cabeza del músculo, y aquel que se une con } \\
\text { la parte, o hueso que ha de ser movida, se llama cola del músculo, y la parte } \\
\text { carnosa, que media entre las dos extremidades, se llama vientre. }\end{array}$ \\
\hline
\end{tabular}

$1744 \quad$ Bernardino Genga

Anathomia chirurgica reformada

1764 Martín Martínez

Anatomía completa del hombre

Hippolyte Cloquet

A system of human anatomy.

1858

Henry Grey

Anatomy descriptive and surgical

1899

Testut

Tratado de a natomía humana
Se llama así según algunos, de la voz $M$ us que significa ratón o t opo desarrollado, porque en la figura se parece a él, y en la cabeza, y cola delgado, y en el medio tumido, o más grueso: tales son algunos músculos, en quien se reconoce esta figura; y así, como dicho animal tienen un movimiento célere, como de palpitación, así también observamos igualmente una celeridad de movimiento en el músculo debajo de la cutis.

Se compone de fibras carnosas, tendones, fibras nerviosas, nervios, arterias, venas, vasos linfáticos y de una membrana común y externa, que lo cubre todo. Los músculos tienen dos tendones, uno atado a la parte firme hacia donde se hace el movimiento; y el otro atado a la parte móvil, que es la que ha de ser traída, o movida.

Órgano esencial del movimiento, está formado por fibras, su característica principal es la contracción, la cual provoca cambios de posiciones parciales en el cue rpo humano.

Órgano de la locomoción, están conformado por manojos de fibras con la propiedad de la contractibilidad. Existe uno voluntario, relacionado con la vida animal y otro involuntario, que participa en la vida orgánica.

Órgano que tiene la propiedad de contraerse. Constituido por fibras estriadas. Compuesto de una parte blanda, roja y contráctil. Y de otra parte blanda, firme y no contráctil, el tendón. Existe uno voluntario, que se contrae bajo la influencia de la voluntad y otro involuntario, que escapa a la influencia de la voluntad. 


\section{DISCUSIÓN}

El objetivo de esta investigación fue analizar en la TH el TM y su contexto histórico para proponer cambios consistentes con los lineamientos de la FIPAT. Para esto, los resultados encontrados se discutirán en relación a las sugerencias realizadas por este Comité, las cuales señalan: i) todas las estructuras morfológicas adyacentes se denominen con una sola palabra; ii) El lenguaje empleado sea el latín; iii) Se describa el elemento de la forma más fiel a los principios de su geometría y forma; iv) Se eliminen las eponimias; v) El término sea congruente, es decir, se permiten derivados y por tanto, se acepta la palabra primitiva que dio origen a aquellos derivados (FIPAT). De este modo, la propuesta a realizar cumplirá con los estándares establecidos, además de considerar la congruencia del término en el tiempo.

Si bien una de las recomendaciones de la FIPAT es que el idioma oficial a utilizar en laterminología sea el latín, $T H$ cuentan con una serie de palabras que tienen su origen en el griego o son una latinización de las mismas. Esta problemática se hace evidente al analizar el TM y las palabras que lo componen. Respecto los encabezamientos principales, tejido muscular liso (textus muscularis levis: textus muscularis nonstriatus) y tejido muscular estriado (textus muscularis striatus), encontraremos que este se complementa con los vocablos liso, del griego $\lambda i \varsigma[\lambda i s$ : superficie que no presenta asperezas, realces o arrugas] y estriado, del latín stria [stria: surco, raya, ranura o acanaladura]. A su vez, de este último término aparecen dos conceptualizaciones secundarias que se complementan con palabras de origen distinto: esquelético, del griego

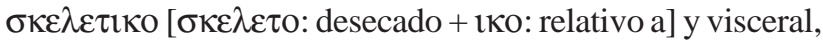
del latín uiscer (a) [uisera: cada uno de los órganos contenidos en las principales cavidades del cuerpo humano]. Por último, el término tejido muscular estriado visceral se subdivide en torno al vocablo cardíaco, el cual tiene su origen en el griego $\kappa \alpha \rho \delta 1 \alpha \kappa o[\kappa \alpha \rho \delta \imath \alpha$ : corazón $+\alpha \kappa o$ : relativo a] (Tabla II). La etimología indica que las palabras liso, esquelético y cardíaco son una latinización de vocablos con origen en el griego. Situación particular es la que ocurre con los términos liso y esquelético, en el caso del primero si bien su origen es en el griego, su equivalencia en latín es levis por tanto, es aceptable y cumpliría con la norma de la FIPAT. Sin embargo, esquelético viene del griego y además si nos ceñimos en su etimología no entrega información relevante para la comprensión de la estructura, aquí una opción sería utilizar la palabra latina osseus [os: hueso + eus: relativo a] que significa relativo a lo óseo, definición mucho más descriptiva y aplicada que la del término esquelético.
Una de las tantas teorías existentes y que explicaría esta combinación de palabras se remonta al antiguo Imperio Romano. En esta etapa los romanos tomaron como presos de guerra a estudiosos griegos, esto trajo consigo una helenización del mundo romano, apropiándose de la estética, costumbres y conocimientos de Grecia. En este tránsito también se adquirieron parte de sus conceptos y otros se latinizaron (Rodríguez, 2003). Además de esto, el griego y el latín, y por tanto todas sus palabras latinizadas, fueron proclamadas por los romanos como las lenguas oficiales del Imperio. Sin embargo, fue solamente el latín el que se mantuvo durante las Edades Media, Moderna y Contemporánea, y fue adoptado por los científicos para la transmisión de conocimientos en las universidades de Europa (García, 2010). Así, sin ser uno de sus objetivos, el latín generó una comunicación entre los conocimientos del pasado y el presente de la terminología (Musil et al., 2015). Complementariamente a lo mencionado, las lenguas griega y latina, otorgan la posibilidad de crear palabras nuevas y por tanto satisfacer las demandas actuales de los términos científicos, esto quiere decir, ser explícitos, exactos, comprensibles y aceptables a nivel internacional (Duque et al., 2002).

Por otra parte, la $T H$ sugiere una sola palabra o el menor número de las mismas para nombrar a toda estructura, esto facilitaría la comprensión y fijación de las estructuras, evitando la memorización y utilización de sinónimos (Vásquez \& del Sol, 2014). Pese a esto, es posible encontrar estructuras con dos o más palabras o inclusive sinonimias en las subordinadas de un mismo término. Específicamente, en una de las subordinadas de tejido muscular estriado visceral, encontramos tejido muscular estriado visceral no cardíaco. Aquí, el concepto estriado visceral no cardíaco sería una redundancia que no aportaría a la comprensión del mismo, debido a que ya se encuentra en la supraordenada. A esto, se suma que etimológicamente este vocablo expresa ubicación y no forma. Por tanto, si apelamos a la sugerencia que indica la utilización del menor número de palabras por estructuras, se abriría un espacio para discutir posibles modificaciones al respecto.

El término debe describir lo más fielmente posible la geometría y forma de la estructura, la $T H$ propone como dos grandes divisiones del TM, tejido muscular estriado (textus muscularis striatus) y tejido muscular liso (textus muscularis levis: textus muscularis nonstriatus). Esto coincide con lo descrito por Junqueira \& Carneiro (2015) y Ross \& Pawlina (2015), quienes dividen al tejido muscular en dos tipos; estriado y liso. Al mismo tiempo, al primero lo subdividen en esquelético, el cual se fija a los huesos, y cardíaco que conforma las paredes del corazón (Junqueira \& Carneiro; Ross $\&$ Pawlina). Por otra parte, el segundo se encontraría en el 
MUÑOZ-COFRÉ, R.; ROA, I.; NICHOLSON, C.; CONEI, D.; PARRA-VÉLIZ, M.; ESCOBAR-CABELLO, M . \& VÁSQUEZ, B. El término músculo y su coherencia interna: Una sugerencia a Terminologia Histologica. Int. J. Morphol., 37(1):128-135, 2019.

sistema vascular y en vísceras mayormente. Esta división se sustentan en su forma, en el caso del músculo estriado. Sus estriaciones se producen por la disposición citoplasmática de los miofilamentos delgados y gruesos. Por otro lado, en el músculo liso no se observan estriaciones transversales debido a que los miofilamentos tienen menos miosina y tampoco logran el orden del músculo estriado (Junqueira \& Carneiro; Ross \& Pawlina). Por tanto, ambos términos cumplirían con entregar información con respecto a la forma de la estructura a la cual se asocian. Por el contrario, las subordinadas que nacen desde tejido muscular estriado, vale decir, tejido muscular estriado esquelético (textus muscularis striatus skeletalis) y tejido muscular estriado visceral (textus muscularis striatus visceralis), y a su vez sus divisiones, músculo estriado cardíaco (textus muscularis striatus cardiacus) y músculo estriado visceral no cardíaco (textus muscularis striatus visceralis non cardiacus), escapan de esta norma debido a que los vocablos esquelético: relativo a lo desecado; visceral: órganos contenidos en las principales cavidades del cuerpo humano; y cardíaco: relativo al corazón, expresan relación y/o ubicación del músculo estriado y no su forma. Esto es concordante con lo planteado por Ross \& Pawlina, que dependiendo de la localización del músculo estriado lo dividen en esquelético, cardíaco o visceral. Así los términos principales, tejido muscular liso y tejido muscular estriado, cumplirían con la norma, no así sus subordinadas, que expresan localización.

Sobre la eliminación de eponimias y consideración de la palabra que dio origen a derivados, al analizar la clasificación propuesta por la $T H$ no se visualiza la presencia de epónimos. En tal escenario, y en relación al objetivo planteado en esta revisión, es necesario examinar los resultados de la búsqueda histórica con el propósito de determinar la congruencia del término y los derivados del mismo. En sus inicios el TM fue asociado al movimiento, según Erasístrato (304-250 a.C.) los músculos eran responsables de este hecho, para esto la neuma llamada "espíritu animal" ubicada en el cerebro a través de los nervios, le indicaba a los músculos contraerse para generar alguna acción determinada (Derenne et al., 1995; De Vitto, 2001). Posteriormente, Galenus (129-216 d.C.) describió al músculo como: "la principal fuente de movimiento, está formado por dos tendones y un centro de carne que amortigua los golpes y cambios de temperatura" (De Vitto, 2001). Hacía especial énfasis en el tendón: un haz de fibras mixtas, que provenía del nervio y los ligamentos, estructuras que le proporcionaban sensibilidad y resistencia mecánica, respectivamente. También pensaba que era el motor del movimiento y que el vientre carnoso sólo tenía funciones complementarias. En 1543 Andreas Vesalius específica, en De humani corporis fabrica, que el músculo está confor- mado por las mismas estructuras descritas por Galenus. Sin embargo, destaca que la carne no era solo una cubierta de las fibras ligamentosas o nerviosas, sino que le dan volumen al músculo permitiéndole acercar sus inserciones, y por lo tanto contraerse, a diferencia de lo planteado por Galenus, que solo le otorgaba una función protectora. Años después Giovanni Borelli (1608-1679), en su libro De Motu Animalium, uno de los primeros textos en describir el movimiento de los animales, analizó el funcionamiento de los músculos incluyendo la matemática y la física. Le asignó funciones distintas a nervios y músculos: los nervios transmitían información desde el cerebro a los músculos, los cuales, por medio de una "fermentación o ebullición" de un material químico propio de este tejido, aumentaba de volumen generando movimiento. Solo un par de años después, la invención del microscopio permitió describir con mayor detalle la microestructura del músculo. Von Leewenhoeck en 1682, interpretó que las estrías observadas a través de este instrumento, eran filamentos alrededor de las fibras musculares y que dentro de estas fibras musculares, existían paquetes de miofibrillas.

En 1664, Niels Stensen publicó su trabajo sobre glándulas y músculos (De musculis et al. glandulis observationum). Realizó observaciones que permitieron avanzar en la comprensión del músculo: los distinguió en rojos o blancos, confirmó que la fibra muscular estaba compuesta de fibrillas unidas entre sí de manera longitudinal y demostró que la contracción muscular la realizaban las fibras musculares no los tendones. Por otra parte, en sus estudios del corazón, afirmó, que sólo bombeaba la sangre y no la producía. De esto, Stensen dijo "El corazón no puede ser una sustancia especial, no es el asiento del calor innato, del alma y no puede producir su propio fluido, la sangre". También dijo que no existían diferencias entre el músculo cardíaco y los que encontramos en el cuerpo, "En cuanto a la sustancia del corazón, creo que puedo probar que no existe nada en el corazón que no se encuentre también en un músculo", y creía que sus movimientos eran automáticos e independiente de la voluntad (Shane Tubbs et al., 2012). En paralelo, Giorgio Baglivi, realizó descripciones clínicas de la fisiología e histología del músculo a través de un microscopio compuesto, distinguió dos tipos de fibras: la motrix (músculos, tendones, huesos) y la membranacea (músculo liso, vísceras). En sus estudios del corazón, concluyó que este se contraía espontáneamente y que las fibras que lo conformaban se encontraban en otros órganos vitales (Bruce, 2002). Estos avances permitieron abrir nuevos espacios de investigación, en cuanto a que reconocen que el corazón está formado por músculo, el cual tendría una contracción autónoma y además sería distinto al encontrado en el resto del cuerpo. Schwann (1839) y Bowman (1840) confirmaron los hallazgos de 
von Leewenhoeck y también los complementaron al determinar que las estrías observadas en la fibra muscular de igual manera se encontraban en las miofibrillas (Caputo, 2011).

Años más tarde, Grey (1858) contribuyó a delimitar la diferencia entre el músculo voluntario o de la vida animal y su relación con el movimiento del cuerpo, y el músculo involuntario o de la vida orgánica, ubicado en órganos como el corazón, esófago y estructuras internas del cuerpo humano. Bajo la misma teorización, Testut describió de manera acabada los músculos de la vida animal, destacando su forma estriada y los músculos de la vida vegetativa con su funcionamiento independiente de la voluntad y ausencia de estrías. En la actualidad autores como Ross \& Pawlina afirman que todos los músculos están conformados por las proteínas contráctiles actina y miosina. Además, tanto el músculo esquelético como el cardíaco cuentan con estriaciones cruzadas por la organización específica de los miofilamentos, situación que no se observada en el músculo liso donde estas son inexistentes.

\section{CONCLUSIONES Y PROPUESTA}

Los principales hallazgos indican que; i) las palabras liso, esquelético y cardíaco tiene su origen en el griego y fueron latinizadas, sin embargo, liso tiene su equivalente en latín que es levis, en el caso del término esquelético proponemos reemplazarlo por osseus, que significa relativo al hueso, ya que es una palabra latina y entrega mayor información para la comprensión de la estructura; ii) el término estriado visceral no cardíaco sería una redundancia; iii) los vocablos visceral y cardíaco expresan relación y/o ubicación del músculo estriado y no forma. Pese a esto, el análisis histórico indica que estos conceptos fueron interiorizados desde el siglo XV y XVI aproximadamente, por lo que sugerir su cambio o eliminación es complejo debido a la cantidad de años que han sido utilizados. En este contexto, sería prudente analizar la posibilidad de ir solamente sobre las redundancias, así el término tejido muscular estriado quedaría con tres subordinadas; tejido muscular estriado óseo, tejido muscular estriado visceral y tejido muscular estriado cardiaco (Tabla IV).

Tabla IV. Propuesta de división del tejido muscular a Terminologia Histologica.

\begin{tabular}{ll}
\hline NOMINA LATINA & EQUIVALENTE EN INGLÉS \\
\hline TEXTUS MUSCULARIS LEVIS: TEXTUS & SMOOTH MUSCLE TISSUE \\
MUSCULARIS NONSTRIATUS & \\
TEXTUS MUSCULARIS STRIATUS & STRIATED MUSCLE TISSUE \\
Cellula myogenica precursoria & Myogenic stem cell \\
Textus muscularis striatus osseus & Osseus striated muscle \\
Textus muscularis striatus visceralis & Visceral striated muscle \\
Textus muscularis striatus cardiacus & Cardiac striated muscle \\
\hline
\end{tabular}

MUÑOZ-COFRÉ, R.; ROA, I.; NICHOLSON, C.; CONEI, D.; PARRA-VÉLIZ, M.; ESCOBAR-CABELLO, M . \& VÁSQUEZ, B. The term muscle and its internal coherence: A suggestion to Terminologia Histologica. Int. J. Morphol., 37(1):123-127, 2019.

SUMMARY: Terminologia Histologica $(T H)$ was prepared following the indications of the International Committee on Anatomical Terminology (FIPAT), however, it is not exempt from errors and inconsistencies. the above information is analyzed in the term muscle (TM) when considering the language in which it is found, the number of words that are used and the words that make up the form of its structure. In this context, the objective of this research was an analysis in the context of TM and its historical context to propose changes consistent with the guidelines of the FIPAT. From the historical point of view, it was originally described as a contractile tissue, with action capable of originating movement; Made up of two tendons and a meat filling. In the Renaissance the ligaments, nerves, veins and arteries were incorporated as part of the tissue and in the nineteenth century the existence of two types of muscle was recognized, voluntary and involuntary; Finally, Testut incorporates the term striated muscle fibers. the main findings indicate that the words smooth, skeletal and cardiac have their origin in the Greek and were latinized, however, the smooth one has its equivalent in Latin that is levis; in the case of the skeletal term, it was proposed to replace it with bone, which means relative to the bone, since it is a laita word and provides more information for the understanding of the structure; the term non-cardiac visceral striatum would be a redundancy; the visceral and cardiac terms express relationship and / or location of the striated muscle and no form. Despite this, the historical analysis indicates that these concepts have been internalized since the fifteenth and sixteenth century, so it has been suggested that the problem has been reduced or reduced. In this context, it would be prudent. muscular striated bone tissue, visceral striated muscle tissue and cardiac striated muscle tissue.

KEY WORDS: Histological Terminology; Muscle; History. 


\section{REFERENCIAS BIBLIOGRÁFICAS}

Bruce Fye, W. Giorgio Baglivi. Clin. Cardiol., 25:487-9, 2002.

Caputo, C. Compendio histórico de fisiología muscular. Venezuela. Diseño y Diagramación. Antonio Machado-Allison, Impresión: Brima Color. 2011.

Cortés, G. F. \& Ureña B. J. Diccionario Médico-Biológico, Histórico y Etimológico. Salamanca, Ediciones Universidad de Salamanca, 2014. Disponible en: http://dicciomed.eusal.es.

Cloquet, H. A system of human anatomy. Edimburgh, Maclachlan and Stewart, 1828

Columbi, R. De Re Anatomica Libri XV. Venice, Typographia N. Beuilacquæ, 1559.

Derenne, J.P.; Debru, A.; Grassino, A.E. \& Whitelaw, W.A. History of diaphragm physiology: THe achievements of Galen. Eur. Respir. J., 8(1):154-60, 1995.

Duque Parral, J. E.; Gómez Arias, N. C. \& Giraldo Ríos, D. P. Nomenclatura anatómica internacional ¿Un horno microondas en el interior de un volcán activo? Med. UPB, 21(1):43-55, 2002.

Alfredo Alessandro de Micheli Serra \& Raúl Izaguirre Ávila. La luminosa trayectoria de un ilustre Académico del siglo XVII. Ciencia, 80-9, 2009.

De Porras, M. Anatomía Galénico-Moderna. Madrid. En la imprenta de la Música, por Bernardo Peralta, 1716.

De Vito, E. Historia de la fisiología del diafragma. La aventura de galeno. Rev. Arg. Med. Respir., 1:57-63, 2001.

Federative International Comittee on Anatomical Terminology (FICAT). Terminologia Histologica, International Terms for Human Cytology and Histology. Philadelphia, Wolters Kluwer/Lippincott Williams \& Wilkins, 2008.

Frixione E. De Matu Propio. Una historia de la fisiología del movimiento. Editores, Siglo XXI, 2000.

García, C. La formación de la terminología anatómica en español (14931604). Tesis doctoral, Universidad de Salamanca 2010.

Giovanni Borelli. De Motu Animalium, 1680.

Gray, H. Anatomy descriptive and surgical. Londres, Impreso por John W Parker and son, 1858

Junqueira, L. \& Carneiro, J. Histología básica. $10^{\text {a }}$ ed. Río de Janeiro, Guanabara Koogan, 2015.

Losardo, R. J.; Valverde Barbato de Prates, N. E.; Arteaga-Martínez, M.; Cabral, R. H. \& García-Peláez, M. I. International Morphological Terminology: More THan anatomy, histology and embryology. Int. J. Morphol., 33(1):400-7, 2015.

Martínez, M. Anatomía completa del Hombre. Madrid, En la imprenta de Bernardo Peralta, 1728.

Micheli-Pellegrini, V. About muscle insertions in man (Proposal for a new nomenclature of striated muscle. Acta otorhinolaryngol. Ital., 31(3):16776, 2011.

Montaña, B. Libro de la anatomia del Hombre. Madrid, Impreso en casa de Sebastián Martínez, 1551.

Montemayor, F. B. G.; Herrera, V. I. \& Soto, P. A. Análisis del uso de la Terminología Anatómica entre los Estudiantes de la Asignatura Anatomía de la Licenciatura en Medicina, de la Facultad de Medicina de la Universidad Nacional Autónoma de México. Int. J. Morphol., 34(4):1280-4, 2016.

Musil, V.; Suchomel, Z.; Malinova, P.; Stingl, J.; Vlcek, M. \& Vacha, M. THe history of Latin terminology of human skeletal muscles (from Vesalius to THe present). Surg. Radiol. Anat., 37(1):33-41, 2015.

Roa, I.; Vásquez, V. \& Contreras, M. Persistencia de Epónimos en Terminología Histológica. Int. J. Morphol., 34(4):1245-52, 2016.

Rodríguez, M. A. El descubrimiento de la teoría en Roma. Nuevas perspectivas de la helenización de la república romana. Gallaecia, 22: $507-$ 29, 2003.

Ross, M. \& Pawlina, W. Histología, texto y atlas. $7^{\mathrm{a}}$ ed. Philadelphia, Wolters Kluwer, 2015.
Tubbs, R. S.; Gianaris, N.; Shoja, M. M.; Loukas, M. \& Cohen Gadol, A. "The heart is simply a muscle" and first description of the tetralogy of "Fallot". Early contributions to cardiac anatomy and pathology by bishop and anatomist Niels Stensen (1638-1686). Inter. J. Cardiol., 154:312-15, 2012.

Testut, L. \& Latarjet, A. Tratado de Anatomía Humana. $9^{\mathrm{a}}$ ed. Barcelona, Salvat, 1969.

Universidad de Salamanca. Dicciomed.eusal.es. Diccionario médico-biológico, histórico y etimológico. Salamanca, Ediciones Universidad Salamanca, 2014. Disponible en: http://dicciomed.eusal.es/ index.php?fecho=Antigua.

Vásquez, B. \& del Sol, M. The Terminologia Histologica in THe medical sciences. Int. J. Morphol., 32(1):375-80, 2014.

Vesalio, A. De humani corporis fabrica. Basilea, 1. Oporinus, 1543.

Wang, Y.; Winters, J. \& Subramaniam, Sh. Functional classification of skeletal muscle networks. I. Normal physiology. J. Appl. Physiol., 113:1884-1901, 2012.

Dirección para correspondencia:

Rodrigo Muñoz Cofré

Avenida Francisco Salazar \# 01145

Universidad de La Frontera

Temuco

CHILE

E-mail: b.munoz13@ufromail.cl

Recibido : 22-09-2018

Aceptado: 15-12-2018 